\title{
Research of Human Resource Ecosystem of Auto Aftermarket Industry During Economic Transformation Period
}

\author{
Chenlei Mao \\ ${ }^{1}$ Jiangxi University of Technology, 330098 Nanchang, China \\ Humao120@qq.com
}

Keyword: Economic Transformation Period; Auto Aftermarket Industry; Human Resource Ecosystem

\begin{abstract}
This paper puts the ecological system theory into human resources management of auto aftermarket industry creatively. Ecosystem model of human resource of auto aftermarket industry is constructed from six aspects. Then, a series of management strategy is designed accordingly.
\end{abstract}

\section{Introduction}

After ten years of groping forward, China's auto industry has entered a transformation period. In the period of economic transformation, with car ownership increasing and the transparency of the automobile marketing, a series of services of auto aftermarket, which includes automotive beauty, car maintenance, car maintenance, auto finance, auto claims, car networking, automotive electronics business, auto detection and second hand car trading, ushered in the great development opportunity. Development and prosperity of auto aftermarket has caused the attached great importance of government and enterprises. More and more auto aftermarket enterprises realized that, focus of enterprise competition changed from disorderly competition to the competition of all kinds of knowledge and intellectual innovation, and competitiveness of human resources became an important guarantee for survival and development of auto aftermarket ind ustry. There fore, how auto aftermarket enterprises attract talents, retain talents, make good use of talents, encourage talents are the core problems of human resource management during economic transformation period.

\section{State-of-the-art}

Auto aftermarket refers to various services around the car in the process after the sales of automobile. It involves a wide range, covering all services after consumers buy a car, including automobile trade (import and export, new car sales, second-hand car sales, lease, auction, e-commerce, etc.) and services (accessories and supplies, car modification, beauty maintenance, inspection and maintenance, auto finance, insurance, auto club, etc.). In the automotive industry chain of the mature markets of Europe, United States and Japan, $20 \%$ of the profits from the vehicle, $20 \%$ from the auto parts, $60 \%$ from the automotive service industry, profits generated after the market are more than double over the previous market. In the current domestic car sales, manufacturing are relatively large proportion, the proportion of service is too small: Accessories accounted for $37 \%$, manufacturers accounted for $43 \%$, retail sales accounted for $8 \%$, services accounted for only $12 \%$. It seems, strong growth of the automobile industry will bring enormous development space for the after-sale market of automobiles.

\section{The characteristics of human resource ecosystem}

Dynamic. Human resource ecosystem will change and adapt with the external environment. The development process of human resource ecosystem can be showed as relations between internal factors 
and external environment. Due to the external environment will continue to change and diversity of internal factor, the ecological system of human resources is very dynamic, including changes of internal and external environment of the enterprise, including change and adapt of personnel for the internal and external environment of enterprises. Accurately grasping the dynamic characteristics can adjust timely and appropriate human resource ecosystem, so as to optimize the structure of enterprise.

Entirety. Human resource ecosystem is a whole system with interactions between human resources system and enterprises, different departments, different positions different levels. In the view of entirety, it can be more reasonable and perfect to optimize the ecosystem of human resources and have a more macro and unified perspective.

Competitiveness. Any high-quality resources is scarce. Demand for quality resources will lead to the fierce competition. The competition of human resource ecosystem can be divided into four kinds of basic types: inner inclusion, intersection, adjacent and separation.

Balance. Human resource ecosystem has biological characteristic, which exists a kind of evolution process from balance to imbalance and then to balance again. When the internal factor cannot adapt to the external environment or internal factors appear imbalance, or it is a lack of coordination, human resource ecosystem changes the bad situation. Generally speaking, the balance of the ecological system of human resources is mainly reflected in two aspects: one is the balance between human resource ecosystem and its dependent environment; the second is the order of balance among internal structures of human resource ecosystem. Human resource ecosystem is not always a passive acceptance of environmental change. On the contrary, it can integrate and deploy human resources according to their own characteristics and the actual situation rationally, in order to better play its functional efficiency.

\section{Ecosystem theory imported into human resource management of auto aftermarket}

How automobile industry market coordinates with the market economic, develops and utilizes human resources effectively and rationally, explores the best match of people and businesses, in order to achieve sustainable development, are becoming the most important question of human resources management of automobile after-sale market industry. On the other hand, the ecology theory is applied in the field of economics and management to study mutual dynamic matching and coordinated development among business, enterprise, ind ustry and market environment, which has been incorporated into the research vision in the field of modern management. If putting the ecological system theory in the ecology into to human resources management of automobile ind ustry market, the result is likely to open up new space for the human resources management, to provide scientific basis and more effective policy recommendations for the healthy and sustainable development of the auto aftermarket.

\section{The construction of human resource ecosystem model in the auto aftermarket}

At present, human resources management of auto aftermarket industry in china is in the general level. In order to make it become a powerful driving force for the rapid development of enterprises, it is necessary to combine its own characteristics, build their own high-quality human resource ecosystem model from the six aspects of human resource, including environment, vitality, mechanism, allocation, strategy and external environment. In this paper, human resource ecosystem model is defined as: excellent atmosphere, rich creative, improving mechanism, reasonable allocation and scientific strategy, a good external environment. These six parts are interrelated and interacted, which constitute the human resource ecosystem of the auto aftermarket.

Optimize atmosphere of human resources management in the auto aftermarket. Management level of leader should be enhanced innovately. In the training of middle-level cadres of enterprise, 
experts and professors' lessons is a main training approach. Rigorous and centralized management is always main management style in automobile after-sale market industry, however, it is important to adjust the organizational structure under the new background of knowledge economy. Leaders and managers must clear human resources management principles which decision-makers decide the direction of development and the department decide details of development.

Improve energy of human resource of auto aftermarket industry. In order to construct knowledge innovation mechanism, the leader should plan the development strategy of the enterprise and various departments with the innovation thought and the long-term strategic vision. The purpose to develop brand casting mechanism is to strengthen brand innovation of auto aftermarket industry, improve brand awareness. To make the brand of service innovation and corporate culture construction closely together, on the one hand, to allow customers to get more benefits and more convenient, on the other hand, to make the auto aftermarket industry get rich corporate culture from the service innovation. To develop internal incentive mechanism, through readjustment and reform of the employment system of personnel and labor, and to set up long-term cooperation incentive system arrangement, in order to provide sufficient space for employees in enterprises.

Improve human resources manage ment mechanism of auto aftermarket industry. To adjust the salary system. In the principle of innovation and enhancing the quality of service, service personnel, technical personnel and marketing personnel are the most important human resources. To improve the work enthusiasm of these employee can cause a significant increase in the benefits of auto aftermarket industry. To broaden the channels of promotion and to allow employees to get full display through the promotion channel widening, so that employees can see their own space for development and connect the future of the enterprise and the future of their own together. The most important is that auto after-sale market industry should introduce competition mechanism. Then, it is also needed to build custom performance evaluation system. The specific index system, unified standards and quantitative, qualitative and comparative analysis will make an objective, fair and accurate comprehensive evaluation.

Create a good external environment for the auto afte rmarket industry. Do publicity and image. To increase publicity efforts in order to create a brand image of enterprises which can make a deep impression on more customers, and improve the corporate social visibility and reputation. To tap the talent potential in order to provide good human resource security for the human resource ecosystem in the auto aftermarket industry.

Allocate human resources by reasonable ways. In order to ensure the healthy development of human resource ecosystem, the competition of enterprises needs to make the best use, which requires enterprises to have the most reasonable and appropriate allocation of human resources, according to its own characteristics. Talent is equipped to play its role in the most positions at the same time in the most appropriate time in the most accurate way. In order to ensure the full play of human resources, enterprises should also create a good positive working environment, which requires the enterprise to build human resource flow and reasonable platform, making human resources timely and appropriately play their own advantages.

Design human resource strategy scientifically. Favourable development of human resources has a direct correlation with human resources strategy, and strategy formulation is according to itself and outside of awareness and change, the optimization of human resource ecosystem needs more scientific reasonable human resource strategy to give guidance. Only better to exert individual latent ability and constantly improve the internal factor of human resource ecosystem can make it be possible to optimize the whole of it. It is necessary to maintain the development of human resource ecosystem through 
maintaining the ecological balance of the human resource management system and the external environment.

\section{Conclusions}

Human resource management is the source of the power of enterprise development, the fundamental guarantee for the sustainable development of enterprises. To optimize the human resource ecosystem as a new and important perspective of human resource management of the enterprise has more realistic significance. Therefore, development of modern society construct is conducive to their own survival and development of human resource ecosystem, and actively explore the ecological system of human resource management strategies, make suitable to the laws of economic development of ecological system of human resources strategy will provided high competitive advantages for enterprises, enhance the attractiveness and create better benefit the common and important initiatives.

\section{Acknowledgment}

This work was supported by Jiangxi Province Office of Education of Humanities and Social Science Research [No. GL 1409]. And the project of Technology Department of Jiangxi Province [No 2013BBE50051] also gives us lots of help.The author thanks Dr. Hu Jian-feng for help.

\section{References}

[1] Yu L, Chen Y. A neural network based method for part demands prediction in auto aftermarket[C]// Software Engineering and Service Sciences (ICSESS), 2010 IEEE International Conference on. IEEE, 2010:648 - 651 .

[2] Collins A. Today's Transactions: Toyota Expands Auto-Aftermarket Reach with \$759M Cascade Purchase[J]. Mergers \& Acquisitions Report, 2012.

[3] Noto A. Winners of the Auto Aftermarket[J]. Mergers \& Acquisitions the Dealermakers Journal, 2012.

[4] Cui L. Grand Gathering of Auto Aftermarket Industry[J]. Chinas Foreign Trade, 2012.

[5] Liu C. The Development of American Auto Aftermarket[J]. Shanghai Auto, 1999.

[6] Gai H, Liu Z. The Intension,Construct and Optimization of Human Resource Management Ecosystem[J]. Ecological Economy, 2010.

[7] Yan A M. Concept, Composition and Self-adaptive Regulation Mechanism of Human Resource Ecosystem[C]// Management Science and Engineering, 2007. ICMSE 2007. International Conference on. IEEE, 2007:1511 - 1516.

[8] Gai H, Liu Z. The Intension,Construct and Optimization of Human Resource Management Ecosystem[J]. Ecological Economy, 2010.

[9] Xie H M, Chen J, Management S O. Review on human resources based on the perspective of ecosystem[J]. Science-Technology and Management, 2014.

[10] Xu Y. Discussion of Fast Repair Chain in the Automotive Aftermarket[J]. Shanghai Auto, 2010.

[11]Bravender R. Customers 'cruise' in to store's success[J]. Aftermarket Business, 2006. 